\title{
Design of Ultra-Wideband Dielectric Resonator Antenna Using Ceramic-Filled PTFE Composites
}

\author{
GUAN-PU PAN, JIUN-DA LIN, TSUNG-LIN LI, JWO-SHIUN SUN \\ Department of Electronic Engineering \\ National Taipei University of Technology \\ 1, Sec. 3, Zhongxiao E. Rd., Taipei 10608 \\ TAIWAN, R.O.C.
}

\begin{abstract}
In this paper, the new dielectric resonator antenna (DRA) is implemented by replacing the traditional dielectric resonator with a new material with low permittivity for ultra-wideband (UWB) application is presented and studied. A hybrid structure DRA was designed with parasitic slot to enhance the impedance bandwidth. The bandwidth met the specification of MB-OFDM for the bandwidth $(3.168 \mathrm{GHz}-4.752 \mathrm{GHz})$. Finally, another antenna structure was designed. By applying the microstrip feed line, UWB and radiation characteristics are achieved. From the measured results, the proposed DRA showed good radiation pattern, high gain, wide bandwidth $(3.03 \mathrm{GHz}-10.7 \mathrm{GHz})$ and compact size. The bandwidth met the specification of MB-OFDM (3.168 $\mathrm{GHz}-10.56 \mathrm{GHz})$.
\end{abstract}

Key-Words: - Dielectric resonator antenna, ultra-wideband, Multiband Orthogonal Frequency Division Multiplexing.

Received: December 1, 2020. Revised: March 27, 2021. Accepted: April 6, 2021. Published: April 19, 2021.

\section{Introduction}

The DRA have taken the attention of researchers due to their characteristics such as high permittivity, low loss, low temperature coefficient, light weight and high-quality factor. In order to enhance the impedance bandwidth, choose the new material with low permittivity to be resonator [1].

In 2002, FCC announced the radio band from 3.1 $\mathrm{GHz}$ to $10.6 \mathrm{GHz}$ for the commercial use of ultrawideband communication. Recently, ultrawideband systems have received a lot of attention for the short-range wireless communication [2-8]. Based on the investigation of electronic device and circuit, high radiation efficiency and compact size are need to be considered together.

In this paper, a new compact ultrawideband dielectric resonator antenna is proposed. The bandwidth program met the specification of MB-OFDM (3168 $\mathrm{MHz}-10560 \mathrm{MHz}$ ). The DRA proposed in this work showed potential for mass production due to the simplicity of the design.

\section{The Hybrid Dielectric Resonator Antenna}

\subsection{Antenna design}

In order to have more great radiated performance, choosing the RO3010 as the resonator that was made by Rogers Corporation. This ceramic material has many advantages, such as consistent dielectric constant, low dielectric loss and low Q-factor. The proposed design of hybrid DRA structure is shown in Fig. 1. The dimensions of the rectangle DR: $\mathrm{H}_{\mathrm{DR}}=$ $1.27 \mathrm{~mm}, \mathrm{~L}_{\mathrm{DR}}=25.03 \mathrm{~mm}$, and dielectric constant of $\varepsilon_{r_{-} \text {DR }}=10.2$. The substrate thickness of $0.8 \mathrm{~mm}$ with a dielectric constant of $\varepsilon_{r_{-} \text {sub }}=4.4$. The feeding line was combined a straight line with a circular patch to enhanced the bandwidth. Adding the parasitic slot to generated the second mode [9-11]. The square ground plane areas are $40 \mathrm{~mm} \times 40 \mathrm{~mm}$. The other parameters of the structure are as follows: $\mathrm{W}_{\mathrm{S}}=31$ $\mathrm{mm}, \mathrm{L}_{\mathrm{s}}=27 \mathrm{~mm}, \mathrm{~W}_{1}=1.5 \mathrm{~mm}, \mathrm{~L}_{1}=14.5 \mathrm{~mm}, \mathrm{~W}_{2}=$ $5 \mathrm{~mm}, \mathrm{~L}_{2}=5 \mathrm{~mm}, \mathrm{r}=2 \mathrm{~mm}, \mathrm{~W}_{3}=1.5 \mathrm{~mm}, \mathrm{~L}_{3}=2.5$ $\mathrm{mm}, \mathrm{W}_{4}=0.5 \mathrm{~mm}, \mathrm{~L}_{4}=0.5 \mathrm{~mm}$, gap $=0.5 \mathrm{~mm}$.

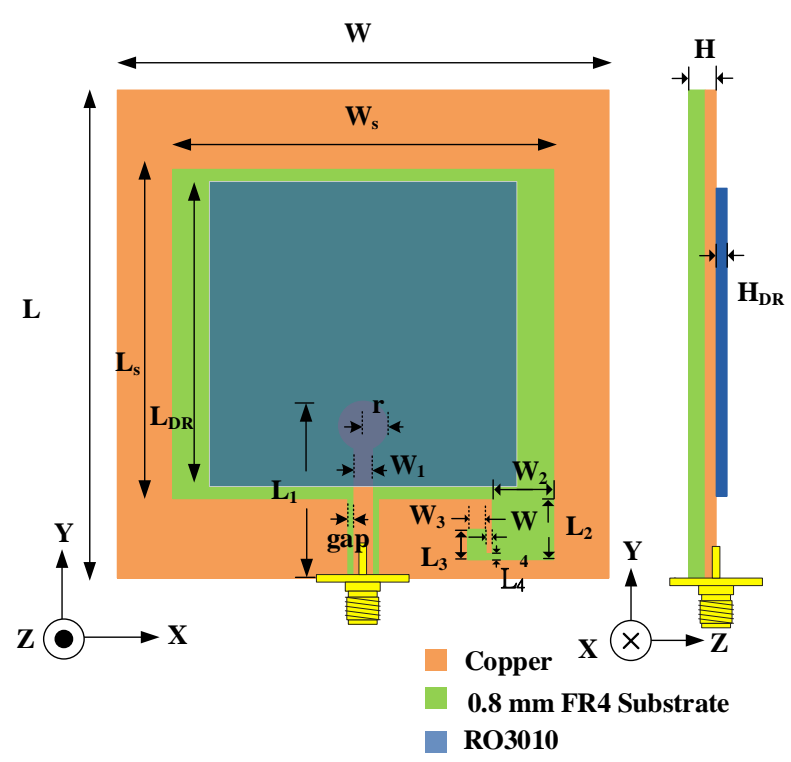

Fig. 1 Structure of dual polarized DRA 


\subsection{Measured Results}

Fig. 2 shows the measured and simulated Sparameter of the proposed DRA. Obviously understand the proposed DRA met the specification of MB-OFDM for the group I (3168 MHz - 4752 $\mathrm{MHz}$ ). However, the main reason for the difference between simulation and measurement is that the placement of the DR during measurement is difficult to be the same as the simulation, and the DR is closely attached to the main structure during simulation, and there is no air layer in the middle, but it is difficult to achieve in actual measurement. Therefore, the matching bandwidth of measurement and simulation is slightly different. But the final measurement result is consistent with the required frequency band. Fig. 3 shows that adding a parasitic slot to the main structure can produce a second resonance mode at $4.55 \mathrm{GHz}$. Advisably adjusting the width of the slot can change the current path, which not only improve the bandwidth but also provide the freedom of design.

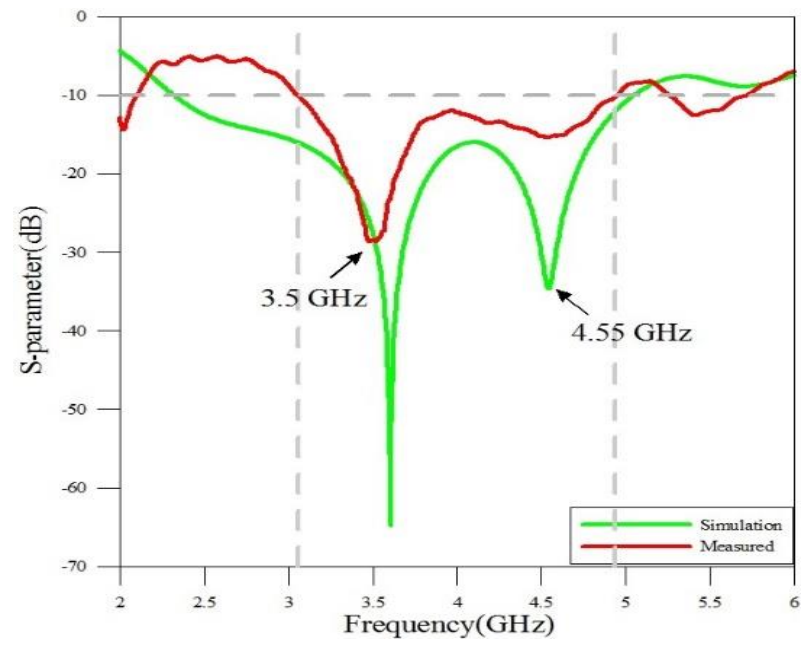

Fig. 2 Measured and simulated S-parameter of proposed DRA

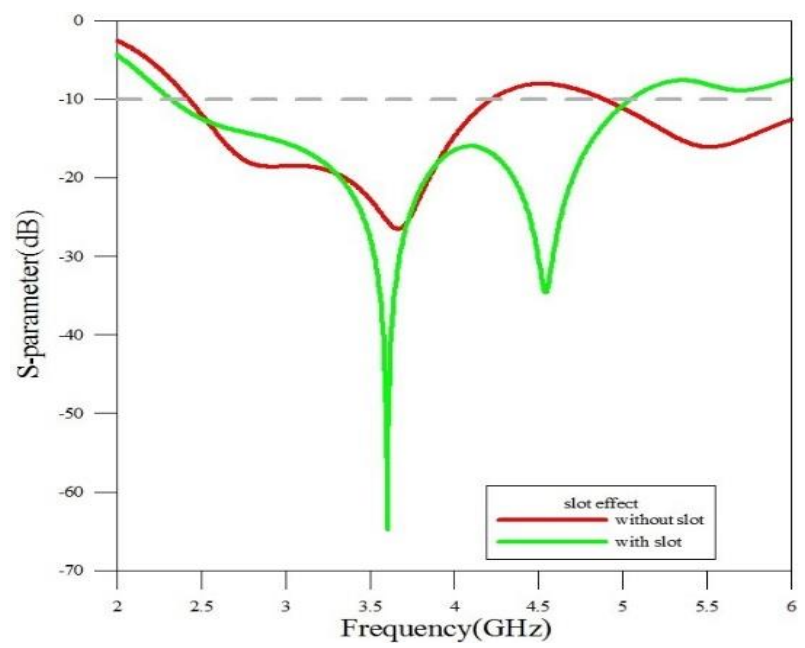

Fig. 3 Effect of adding parasitic slot on S-parameter
Fig. 4 shows the measured E-field and $\mathrm{H}$-field radiation patterns at the frequency of $3.5 \mathrm{GHz}$ and $4.55 \mathrm{GHz}$. The peak gain is $3.4 \mathrm{dBi}$ at $3.5 \mathrm{GHz}$; another peak gain is $2.7 \mathrm{dBi}$ at $4.55 \mathrm{GHz}$.
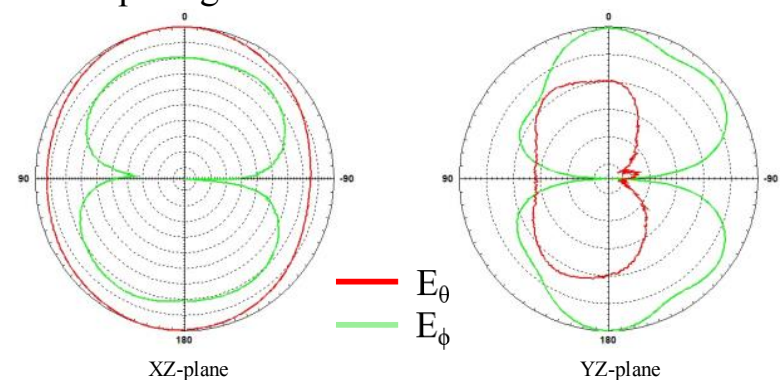

(a)

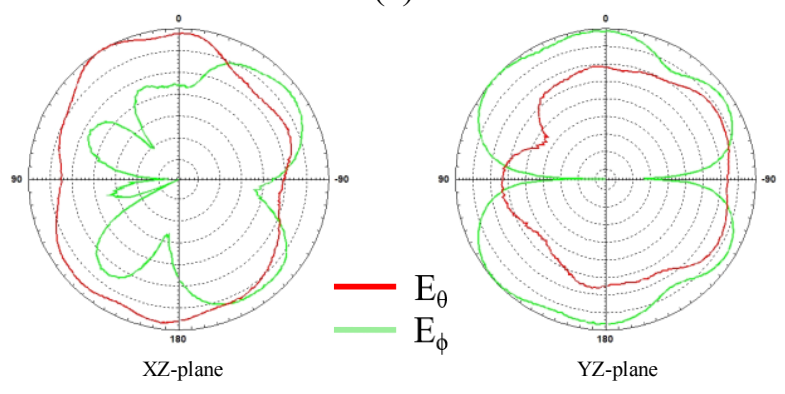

(b)

Fig. 4 Measured radiation patterns: (a) $3.5 \mathrm{GHz}$; (b) $4.55 \mathrm{GHz}$

\section{Ultrawideband Dielectric Resonator Antenna}

\subsection{Antenna design}

In order to increase the impedance bandwidth, the proposed antenna adopt the microstrip line to be the feeding mechanism. Because of boundary conditions, the coplanar waveguide can interfere the radiation of the DR. Fig. 5 shows the geometry of the ultrawideband DRA. The dimensions of the rectangle DR: $H_{\mathrm{DR}}=1.27 \mathrm{~mm}, \mathrm{~L}_{\mathrm{DR}}=30 \mathrm{~mm}$, and dielectric constant of $\varepsilon_{\text {r_DR }}=10.2$. The T-shaped feeding line was used to induce the coupling. The rectangle ground plane areas are $48 \mathrm{~mm} \times 40 \mathrm{~mm}$. The other parameters of the structure are as follows: $\mathrm{W}_{1}=1.5$ $\mathrm{mm}, \mathrm{L}_{1}=23 \mathrm{~mm}, \mathrm{~W}_{2}=12 \mathrm{~mm}, \mathrm{~L}_{2}=1 \mathrm{~mm}, \mathrm{~W}_{3}=30$ $\mathrm{mm}, \mathrm{L}_{3}=9 \mathrm{~mm}$. 


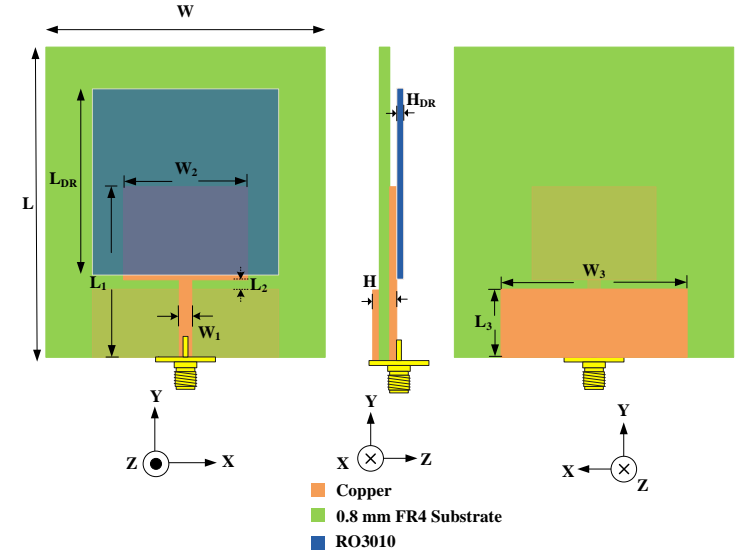

Fig. 5 Structure of ultrawideband DRA

\subsection{Measured Results}

Fig. 6 shows the measured and simulated Sparameter of the proposed DRA. Discrepancies between the simulated and the measured results may be attributed to the tolerance of the fabrication; However, The proposed antenna still met the specification of UWB.

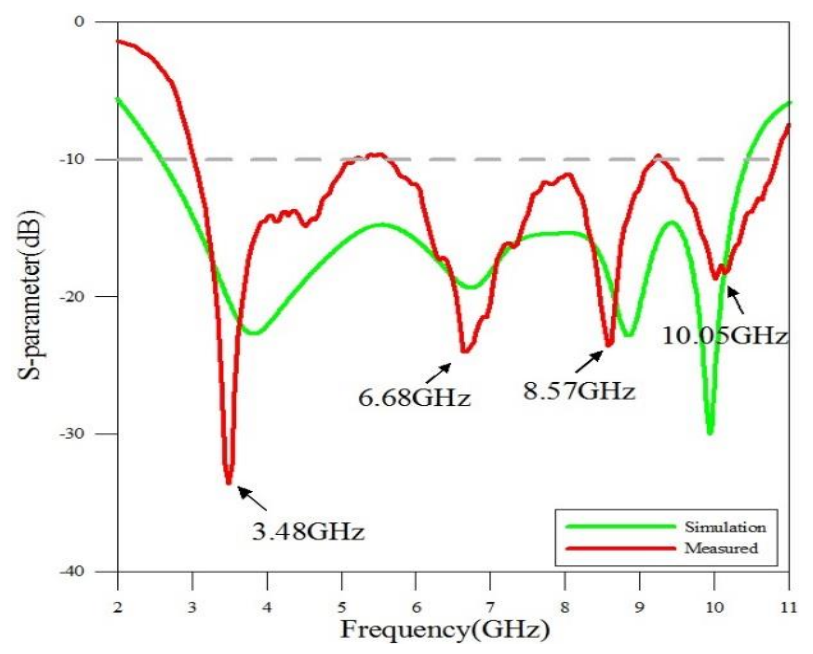

Fig. 6 Measured and simulated S-parameter of proposed Antenna

Fig. 7 shows the effect of the dimension $\mathrm{W}_{2}$. As the width increasing, the number of the resonated mode is varied from 2 to 4 . Fig. 8 shows the effect of the distance between the patch and the ground plane. Changing the dimension $\mathrm{L}_{2}$, it can effectively improve the coupling of the high-order mode.

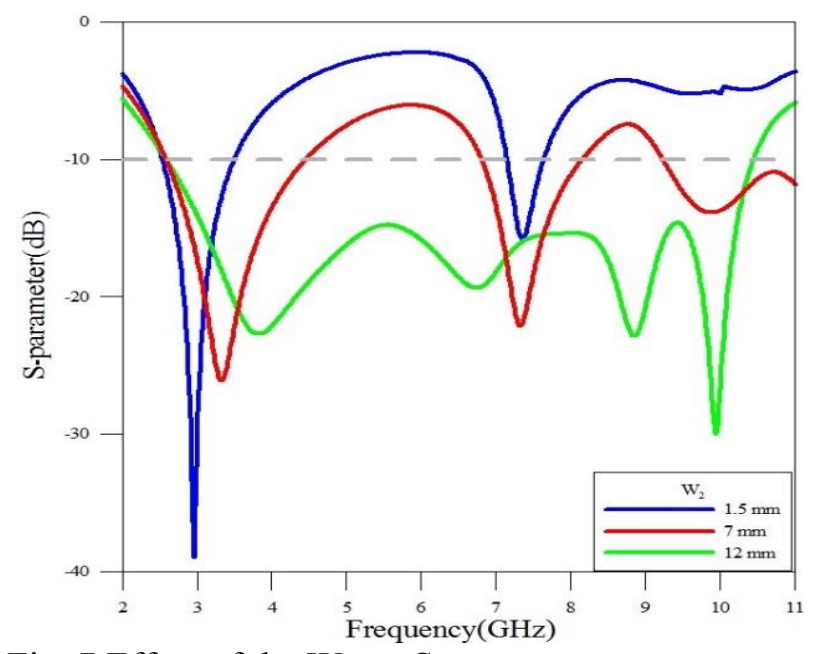

Fig. 7 Effect of the $\mathrm{W}_{2}$ on S-parameter

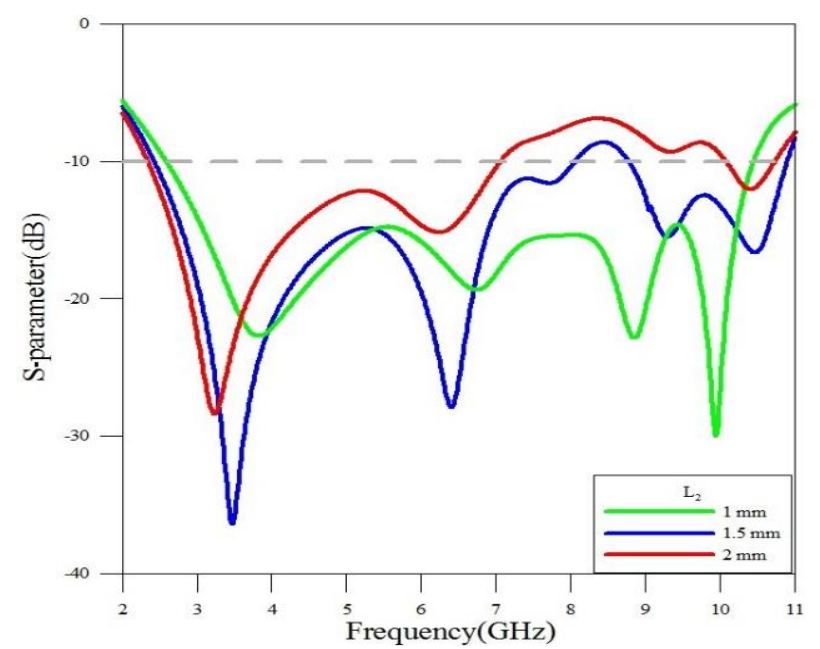

Fig. 8 Effect of the $\mathrm{L}_{2}$ on S-parameter

Fig. 9 shows the radiation patterns of E-field and $\mathrm{H}-$ field at the frequency of $3.48 \mathrm{GHz}, 6.68 \mathrm{GHz}, 8.57$ $\mathrm{GHz}$ and $10.05 \mathrm{GHz}$. The radiation patterns of the $\mathrm{x}-$ $z$ plane are all omnidirectional. This radiation pattern shows that using DR to design UWB antennas has greater practical value. The reason is that in the design of general metal antennas, the high frequency band is caused by the frequency doubling effect of the low frequency band. Therefore, many zero points in the radiation pattern of the high frequency band, which is not suitable for practical applications. However, the radiation mechanism of DR is caused by resonance between materials. Therefore, there is no frequency doubling effect, and there are not too many zero points in the radiation pattern. In terms of practicality, this UWB antenna have practical value. The peak gain is $5.2 \mathrm{dBi}$. 

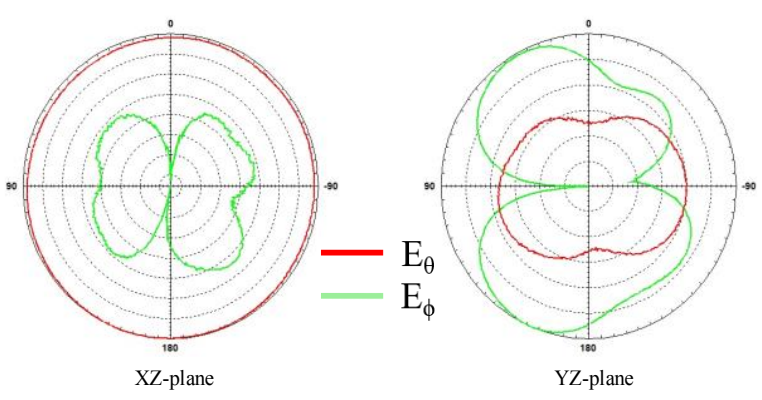

(a)
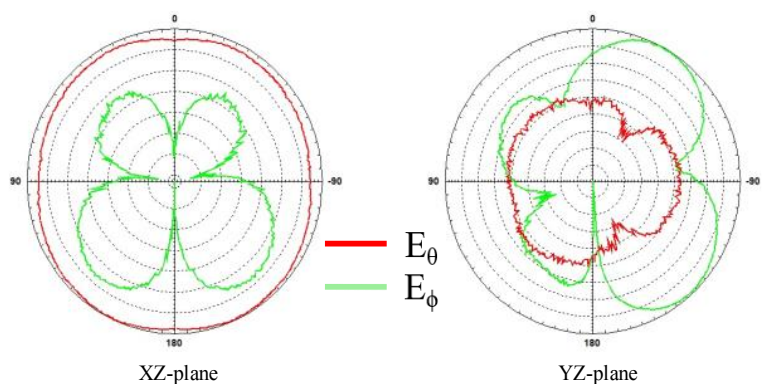

(b)
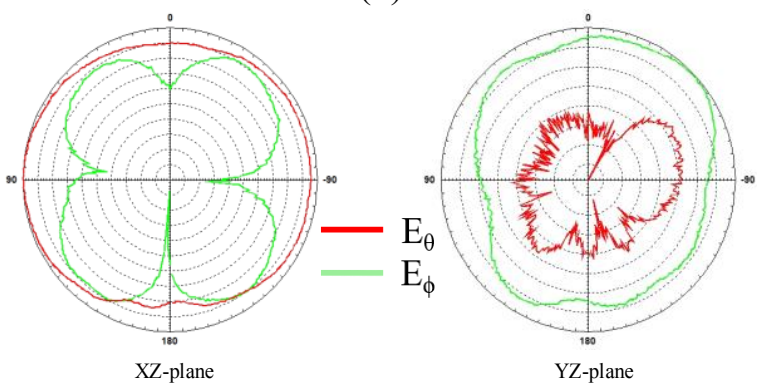

(c)
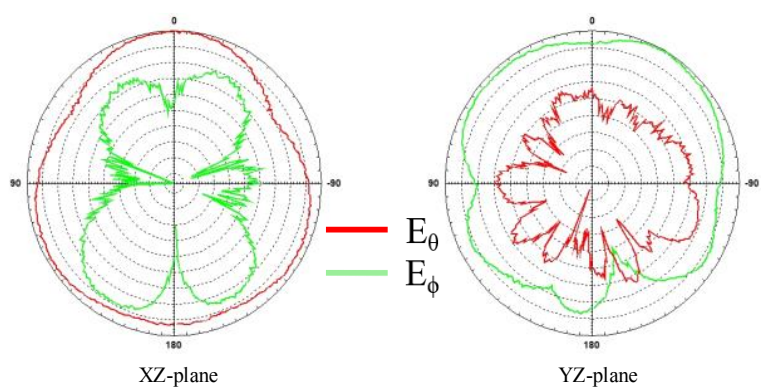

(d)

Fig. 9 Measured radiation patterns: (a)3.48 GHz, (b)6.68 GHz, (c)8.57 GHz, (d)10.05 GHz

\section{Conclusion}

In this paper, a compact DRA with great radiation pattern for ultrawideband application was presented. Improvement of bandwidth is achieved by adjusting the parameters of antenna. The measured results show the proposed antenna met the specification of UWB (3.168 GHz - $10.560 \mathrm{GHz})$. The antenna system proposed in this work showed potential for mass production due to the simplicity of the design. References:
[1] D. Kajfez and P. Guillon, Dielectric Resonators, Artech House, 1986.

[2] C. Ozzaim, F. Ustuner, and N. Tarim, Stacked Conical Ring Dielectric Resonator Antenna Excited by a Monopole for Improved Ultrawide Bandwidth, IEEE Trans. Antennas Propag., Vol. 61, No. 3, 2013, pp. 1435-1438.

[3] T. A. Denidni, W. Zibin, and M. N. Jazi, ZShaped Dielectric Resonator Antenna for Ultrawideband Applications, IEEE Trans. Antennas Propag., Vol. 58, No. 12, 2010, pp. 4059-4062.

[4] M.Abedian, S. K. A. Rahim, and M. Khalily, Two-Segments Compact Dielectric Resonator Antenna for UWB Application, IEEE Antennas and Wireless Propag. Letters, Vol. 11, 2012, pp. 1533-1536.

[5] M. Abedian et.al., Novel Design of Compact UWB Dielectric Resonator Antenna with Dual-Band-Rejection Characteristics for WiMAX/WLAN Bands, IEEE Antennas and Wireless Propag. Letters, Vol. 14, 2015, pp. 245-248.

[6] S. K. Podilchak et.al., A Compact Wideband Dielectric Resonator Antenna with a Meandered Slot Ring and Cavity Backing, IEEE Antennas and Wireless Propag. Letters, Vol. 15, 2016, pp. 909-913.

[7] P. F. Hu et.al., A Compact Quasi-Isotropic Dielectric Resonator Antenna with Filtering Response, IEEE Trans. on Antennas and Propag., Vol. 67, No. 2, 2019, pp. 1294-1299.

[8] N. Yang, K. W. Leung, Compact Cylindrical Pattern-Diversity Dielectric Resonator Antenna, IEEE Antennas and Wireless Propag. Letters, Vol. 19, No. 1, 2020, pp. 19-23.

[9] H. M. Chen et.al., A compact dual-band dielectric resonator antenna using a parasitic slot, IEEE Trans. Antennas Propag., Vol. 8, 2009, pp. 173-176.

[10] L. Lu et.al., Wideband Circularly Polarized Antenna with Stair-Shaped Dielectric Resonator and Open-Ended Slot Ground, IEEE Antennas and Wireless Propag. Letters, Vol. 15, 2016, pp. 1755-1758.

[11] M. Zou, J. Pan, and Z. NieA, Wideband Circularly Polarized Rectangular Dielectric Resonator Antenna Excited by an Archimedean Spiral Slot, IEEE Antennas and Wireless Propagation Letters, Vol. 14, 2015 , pp. 446-449.

\section{Creative Commons Attribution License 4.0 (Attribution 4.0 International, CC BY 4.0)}

This article is published under the terms of the Creative Commons Attribution License 4.0

https://creativecommons.org/licenses/by/4.0/deed.en_US 